\title{
6
}

\section{Doing Faculty Development as if We Value Learning Most: Transformative Guidelines from Research to Practice}

\section{Thomas A. Angelo}

DePaul University

If producing high-quality student learning is American higher education's defining goal, how can faculty development best contribute to its realization? In response to that question, this essay synthesizes theories, findings, and strategies from a variety of literatures into seven transformative ideas which, taken together, have the potential to make our mental models of and approaches to faculty development more effective. It also offers seven guidelines based on these ideas, as well as related, practical strategies for doing faculty development as if student learning matters most.

\section{INTRODUCTION}

Caveat lector. References to transformation in the title and throughout this paper are not casually made. Transformation denotes significant, qualitative change, not merely tinkering with, adding on, or moving bits about. Given its transformative perspective, this essay will be of little use to readers looking for simple, quick, or easy solutions. Instead, it is written for those convinced that their institutions can and, indeed, must provide more effective teaching, produce more and better learning, foster more meaningful scholarship, and operate in a more collaborative fashion. At the same time, it is written for faculty developers with high but realistic expectations, those who recognize that meaningful, transformative change typically requires years of well-conceived, well-led, sustained effort. 


\section{Why Haven't We Made More Progress?}

Since the beginnings of the current higher education reform movement in the mid-1980s, thousands of American faculty developers, administrators, and faculty leaders have promoted change under the banners of assessment, continuous quality improvement, active learning, strategic planning, distance education, and other related movements. Much has changed as a result of their efforts and much has improved, of course. Nonetheless, there are still surprisingly few well-documented examples of significant, lasting gains in student learning at the department or institutional level. More broadly, nearly 30 years of organized faculty development efforts in the US have reaped rather modest rewards, if evidence of improved student learning is the relevant indicator.

\section{Five Possible Reasons}

Why is it that the vast majority of well-intentioned change efforts in American higher education seem to result in little or no long-term improvement in student learning? Peter Ewell offers two compelling reasons: "They [the change efforts] have been implemented without a deep understanding of what 'collegiate learning' really means and the specific circumstances and strategies that are likely to promote it. [and] They have for the most part been attempted piecemeal both within and across institutions" (1997, p.3). This essay suggests three additional, related reasons. A third reason is that most faculty development models in the past have stressed changing what the teacher does, rather than understanding and changing what the students do. As Biggs notes: "Aligning practice on the basis of what students should be doing is likely to be more fruitful than focusing only on what teachers and administrators do (1999, p. 74). Fourth, most American academic change efforts have not acknowledged or addressed the legitimate reasons faculty have for resisting change. Simply put, many faculty fear that attempts to increase productivity and promote learning-centered practice will undermine scholarship and academic freedom, two deeply held values in academic culture; at the same time, few believe that more attention to teaching and learning will lead to more rewards or recognition. And, fifth, academic change efforts in the US are too often peripheral to the institution's core strategic plans and, therefore, unsupported or undersupported by top management.

If the above diagnosis is correct, then faculty developers who simply rededicate themselves to working harder-doing more of the same-are unlikely to reap better outcomes than their predecessors. Instead, if we are to move from tinkering to transformation, it may be time to rethink 
and perhaps even replace some of our traditional ideas about academic change and improvement and the strategies that flow from them. If we value learning most, then transformation is clearly required.

\section{Key Assumptions}

The remainder of this essay rests on six key assumptions. First, it assumes that a central, if not the primary goal of faculty development is to promote high-quality, deep learning by helping faculty help their students learn more effectively and efficiently than they would on their own. Second, it assumes that shared purpose matters, that an academic unit will more likely succeed in providing high-quality teaching and producing high-quality learning if its students, faculty, and the relevant administrators explicitly agree on that goal and work together toward realizing it. Third, it assumes that effective collaboration toward shared goals is still far from the norm in most universities. To make it so would require a transformation in the ways academic administrators, staff, and students think about and carry out their daily work. Fourth, it views academic departments as the most promising units of instructional reform and heads of departments as the natural leaders in transforming departmental cultures. Fifth, it asserts that the academic profession collectively knows a great deal about promoting effective teaching, learning, collaboration, and change in higher education, and that guidelines based on this knowledge from research and practice can orient our efforts toward success. And lastly, the essay assumes that faculty developers, in their roles as "metaprofessionals" (Candy, 1996, p. 17), are best placed and prepared to help department chairs and faculty identify shared goals, learn to collaborate effectively toward those goals, and apply existing knowledge to specific disciplines and contexts in order to improve student learning.

\section{SeVen Transformative Ideas}

This essay draws together a diversity of perspectives, theories, concepts, terms, and strategies from a range of literatures-among them cognitive science, higher education, psychology, and management. Referred to below as transformative ideas, they are the social construction of knowledge, mental models, the learning paradigm, learning productivity, learning communities, the scholarship of teaching, and assessment. These seven ideas, taken seriously and together, have the potential to help us transform our mental models and standard practices. They can help us 
construct a new and transformative vision, or metaphor, of academic departments (and institutions) as productive, scholarly learning communities. A productive department, in this vision, is one that helps students and faculty to produce demonstrably high-quality learning. The scholarly aspect of the vision is well-expressed by Boyer: "What we urgently need today is a more inclusive view of what it means to be a scholar-a recognition that knowledge is acquired through research, through synthesis, through practice, and through teaching" (1990, p. 24). And in a learning community, students and faculty collaborate to achieve shared, significant learning goals (Angelo, 1997, p. 3). This vision is very similar to that expressed by Candy in his discussion of "the university as a learning organization" (1996, p. 10).

\section{The Social Construction of Knowledge}

Simply put, the constructivist view of learning is that humans learn not primarily by receiving and copying impressions and information from the world, but rather by constructing and reconstructing our own mental conceptions of the world. As Piaget (1975) and many others have noted, we often force and distort new information and experience to fit our existing conceptions-or reject them outright if they do not fit. Social constructivists agree that meaning is largely internally constructed, but they stress that shared meanings-socially constructed and negotiatedare necessary for human communication and society. An academic discipline, with its (largely) shared concepts, dialect, and culture is a paramount example of socially constructed and continually reconstructed knowledge.

Constructivism is arguably the dominant model of human learning in educational psychology today. The transformative power of social constructivism inheres both in its rejection of the traditional transmission of knowledge and banking metaphors, and in its assertion that learners must construct knowledge, understanding, and meaning for themselves. This construction is accomplished largely through interaction and negotiation with the world and other humans-including faculty, other students, and authors living and dead. (See Chapter 7 in Belenky, Clinchy, Goldberger, \& Tarule, 1986.) For faculty, this means that students, in order to learn deeply, must become active partners in the construction of their learning. Similarly, faculty developers intent on change must engage their colleagues in constructing or adapting new, shared, contextually relevant concepts, rather than presenting faculty with imported prefabricated mental models for adoption. 


\section{Mental Models}

In The Fifth Discipline, Peter Senge defines mental models as “. . deeply ingrained assumptions, generalizations, or even pictures or images that influence how we change the world and how we take action" (1990, p. 8). Senge argues that building a learning organization requires us to reflect on, make explicit, reconsider, and sometimes redesign these implicit mental models (1990, pp. xiv \& xv). The transformative implication here is that our existing mental models must often be socially deconstructed before change can occur. In relation to the corporate world, Senge notes, "Many insights into new markets or outmoded organizational practices fail to get put into practice because they conflict with powerful, tacit mental models" (1990, p.8). For the academic developer, as for the lecturer, acknowledging and making explicit those implicit mental models is a necessary first step toward new learning. For example, many teachers and students still tacitly believe that learning occurs by transmission; thus, the continuing appeal of the noninteractive lecture to both groups. Before these students and teachers can see the value of alternate, highly interactive approaches, they must be open to questioning their preexisting model of learning.

\section{The Learning Paradigm}

In a widely read and discussed article, Robert Barr and John Tagg (1995) argued that American higher education is undergoing an industry-wide paradigm shift, a transformation from a faculty-and teaching-centered to a student- and learning-centered model. As Barr and Tagg see it, the primary purpose of higher education - and, by extension, of academic departments-in this new paradigm will be producing learning, not providing instruction. By shifting the focus from a means (teaching) to the intended end (learning), Barr and Tagg redefine classroom teaching as only one of several possible means for producing learning. Inherent in the learning paradigm is a radical shift from the usual quantitative, credit hour- and headcount-based models of undergraduate education to a more qualitative, competency, and mastery based view. If institutions can be thought of as producing learning, then raising questions about their levels of learning productivity-and not just about numbers of graduates or credit units generated-begins to make sense.

\section{Learning Productivity}

This phrase has multiple and overlapping meanings (Poulsen, 1995), starting with the dreaded doing more with less. In this essay, however, 
learning productivity means promoting more, deeper, and better learning with the resources available. It requires that we work more cost- and time-efficiently to the extent we can do so without sacrificing learning quality. To be useful, a model of learning productivity requires that we develop clear goals, criteria, and standards for learning production, as well as means to assess and measure outputs. (See also Johnstone, 1993.)

\section{Learning Communities}

While various definitions exist, most center around a vision of faculty and students working together systematically toward shared, significant academic goals. Collaboration is stressed, competition deemphasized, and both faculty and students must take on new, often unfamiliar roles. The faculty member's primary role shifts from delivering content to designing learning environments and experiences, and to serving as coach, expert guide, and role model for learners. In a learning community, the student's role changes as well, from relatively passive observer of teaching and consumer of information to active co-constructor of knowledge and understanding (See Gablenick, MacGregor, Matthews, \& Smith, 1990; Angelo, 1997; Tinto, 1997; and Cross, 1998.)

\section{The Scholarship of Teaching}

While this phrase originally referred to only one of the four categories Ernest Boyer promoted in Scholarship Reconsidered (1990)-the other three being the scholarships of discovery, of integration, and of application-the scholarship of teaching soon became shorthand for expanded and more diverse visions of faculty roles. The transformative thrust of this idea comes in valuing a broader range of scholarly activity (Rice, 1991), and in finding ways to make those activities public, accessible to others, and open to evaluation by peers-as the products of the traditional scholarship of discovery, publications and grants, already are (Glassick, et al., 1997).

\section{Assessment}

Palomba and Banta define assessment as ". . . the systematic collection, review, and use of information about educational programs for the purpose of improving student learning and development" $(1999$, p. 4). Central to this model is the belief that our assumptions about learning outcomes should be empirically tested and that our claims should be based in evidence. Even a quick look at the unsupported claims made in 
almost any university's public relations materials will show how distant this goal remains.

Drawing on the ideas discussed above, the next section offers faculty developers seven practical guidelines for transforming academic units into more productive, scholarly learning communities. Following each of these broad guidelines are specific suggestions for promoting scholarly collaboration among students and faculty in order to improve learning.

\section{Seven Guidelines for Developing Productive and Scholariy Learning Communities: Suggestions AND RESOURCES}

\section{1) Build Shared Trust: Begin by Lowering Social and Interpersonal Barriers to Change}

Most of us learn little of positive or lasting value from people we do not trust. To form a productive departmental learning community, then, faculty must come to trust each other, their head, and their academic developer. The same is true of student-student and student-faculty relations. As Ramsden argues: "Genuine learning requires an atmosphere of trust and an absence of fear; in these circumstances academics, like their students, take risks, improve, and do remarkable things" (1998, p. 268). There are many academic units, no doubt, where such an atmosphere does not currently exist. Nonetheless, it is possible, with time and effort, to create a positive climate for improvement in most departments. And helpful resources exist. For example, in Chapters Eight and Nine of Strengthening Departmental Leadership, Lucas (1994) provides many practical suggestions for team building and conflict management with faculty. In Chapters 3 and 22 of Teaching Tips (1999), McKeachie provides analogous ideas for building classroom community with students.

As a simple first step in trust-before turning to problems, tasks, and issues to be resolved-faculty developers might take time to highlight what faculty are already doing well, and to share successful strategies. Encouraging staff to provide examples of successful teaching and learning experiences allows them to present their best face, and demonstrates that each is an intelligent, capable person with ideas to contribute to the good of the whole.

After faculty have jotted down answers to the questions above, they break into five- to seven-person groups. Each person has no more than three minutes to tell his or her story, and all are encouraged to look for common themes among the examples. Those common themes can then 
FIGURE 6.1

\section{Sharing Lessons Learned from Successful Teaching}

Directions: Focus on a specific unit, lesson, concept, or skill that you teach particularly well. With that successful experience in mind, take the next five minutes to jot down answers to the six questions below. As you write, prepare to explain your example to your colleagues in the small group in no more than three minutes.

1) What course is your example taken from?

2) What exactly were you trying to teach? (What was your main teaching goal or objective?)

3) How did you teach it? (What, specifically, did you do that promoted success?)

4) How did you know your students had learned it? (How did you assess/evaluate their achievement of your goal?)

5) What did you learn, as a teacher, from that experience?

6) What is the big lesson (general principle) about effective teaching and learning that your example illustrates? Put another way, why did what you did work so well? (How would you explain this to a beginning teacher?)

be mined for transferable lessons in a subsequent whole group discussion. With attention to time limits, this exercise can easily be completed in three-quarters of an hour. More ambitious faculty developers may want to capture and document the good examples to share more widely. Whatever the means, the big point here is to start, not with problems and debate, but by attending to faculty members' needs to feel respected, valued, safe, and in the company of worthy, smart, well-intentioned peers.

\section{2) Build Shared Motivation: Collectively Determine} Goals Worth Working toward and Problems Worth Solving - and Consider the Likely Costs and Benefits

Once a working level of shared trust has been established, the academic developer can begin to develop a shared learning improvement agenda. Most of us work more productively if we have clear, personally meaningful, reasonable goals to work toward. Students in courses and faculty in 
departments accomplish more when they share some learning goals in common. While students and faculty typically do have goals, they rarely can articulate clearly what those goals are, rarely know how well they match their peers' goals, and rarely focus their goals on learning. Faculty goals often focus on what they will teach, rather than what students will learn and how, and students goals often focus on getting through and getting on. Thus, since goals powerfully motivate and direct our behavior (Stark, et al., 1989, p. iii), developing a set of shared learning goals is a logical next step in building a productive learning community.

There are many techniques for determining goals (see, for example, Palomba \& Banta, 1999, Chapter 2), but the key is to discover or develop learning-related goals in common. The "Teaching Goals Inventory," developed by $\mathrm{K}$. Patricia Cross and me, is a noncopyrighted, quick, selfscorable questionnaire to help faculty identify their most important instructional goals (Angelo \& Cross, 1993, pp. 393-397.) An even simpler approach is to ask faculty to list two or three things they would like to learn in the coming year or that they would like to make certain the department's students learn well before graduating - and then to look for common goals across the lists. Whatever the shared goals are, in order to be useful they must be clear, specific, linked to a time frame, feasible, and most important, significant.

Goals are not always sufficient to motivate us to learn. After all, if the status quo is not problematic, why change? But neither do all problems provide useful starting points. As Ewell notes, "Maximum learning tends to occur when people are confronted with specific, identifiable problems that they want to solve and that are within their capacity to do so" (1997, p. 4). It is critical, in any case, to connect and frame problems within a larger vision of shared goals, so that energies and resources are not dissipated in myriad efforts that add up to little or no improvement.

Once shared goals have been established, identifying related problems can be more fruitful. The following is a three-step exercise for use with faculty and students to identify promising problems. First, once you have a problem in mind, write down what you think the best solution would be. Second, assuming that were the solution, could the group actually implement it? And third, even if it could be implemented, would the group choose to do so? If the answer to either of the latter questions is "no," it is probably not a problem worth taking on. If the answers are "yes," on the other hand, then it is time for a cost-benefit analysis-however informal - of the proposed solution. I recommend trying to guesstimate the following types of costs before committing to a problem: 
human time and effort, financial resources, costs in political capital, and opportunity costs. That is, what other important problems will you be unable to deal with if you follow this course?

\section{3) Build a Shared Language: Develop a Collective Understanding of New Concepts (Mental Models) Needed for Transformation} Given that most of us assume we are speaking Standard English, it is surprising how often we fail to understand one another. In fact, however, even those of us who are native English speakers regularly use disciplinary dialects-environmental biology, literary studies, social psychology-as well as unique, personal idiolects in the classroom. Building a shared vision for transformative change requires shared mental models and shared language for describing and manipulating those models. That often requires building a shared group dialect, or at least some shared vocabulary. In other words, before we can collaborate productively to build learning communities, we must establish what we mean by key terms such as learning, community, improvement, productivity, or assessment. Taking this step will allow us to make explicit any implicit conflicts among our mental models.

A simple strategy for uncovering different mental models is to ask faculty to describe or define in writing what they mean by one of the terms that is central to departmental goals. Let us say the term is assessment. Then collect those responses and discuss them or create a concept map from them, making visually apparent the areas of agreement and difference. You may find that assessment means, variously, standardized testing, student ratings of faculty, marking, institutional research, or time wasted to the various individuals. Rather than contesting these preexisting definitions, you might suggest the adoption of an additional, shared working definition, much like adding another meaning after a word listed in a dictionary. This add-on strategy does not require that individuals give up their existing mental models, something many will resist. Instead it only requires that they acknowledge differences between their models/meanings and the group's and that they use the group model when collaborating.

\section{4) Design Backward and Work Forward: Work Backward from the Shared Vision and Long-Term Goals to Determine Outcomes, Strategies, and Activities}

Backward design simply means starting with the desired end, goal, or overall vision, then determining the related outcomes and the best means 
to reach them. Typical departmental curricula, as a counterexample, have been designed forward-or more accurately, not designed, but built forward. That is, the faculty usually decide which courses we want to teach and how we want to teach them, then we pile all our courses up and try to construct a curricular rationale for the pile. As an alternative, Wiggins and McTighe (1998) propose a three-stage backward design process: 1) "identify desired results, 2) determine acceptable evidence, and 3) plan learning experiences and instruction" (p. 9). Backward design-which is basically the same model underlying the assessment process and strategic planning-presupposes shared trust, goals, and mental models.

\section{5) Think and Act Systematically: Understand the Advantages and Limitations of the Larger System(s) within which We Operate and Seek Connections and Applications to Those Larger Worlds}

Senge writes "Systems thinking is a discipline for seeing wholes. It is a framework for seeing interrelationships rather than things, for seeing patterns of change rather than static snapshots" (1990, p. 68). The main point here is that all of us operate within larger contexts, which affect and are often affected by our actions. It is relatively common in academic life for individuals or departments to make decisions and changes independently that end up causing ripples, or even crises, throughout the larger organization. Many of us have found our daily working lives unexpectedly and negatively affected by decisions made by the campus's information technology managers. For example, a simple, cost-efficient central administration decision not to continue supporting a particular software package or operating system can have devastating impacts on the research of a few faculty.

Academic departments, of course, are systems within systems. Consequently, there are some limits to the amount and type of change an individual department can initiate or maintain. For example, few departments could, on their own, move to a totally qualitative, competencybased curriculum without dramatically compromising their students' likelihood of graduating. Ewell notes that systems thinking “. . . first demands a comprehensive audit of current and contemplated policies, practices, and behaviors. It also requires a detailed analysis of current values and rewards and how these will inhibit or support desired changes" (1997, p. 6). One simple way to begin this systems audit process is to draw a diagram of all those within, and perhaps outside, the university with whom the department engages and to determine the likely impact of proposed changes on each entity. It is usually sufficient to estimate the likely 
impact on each person or office using a scale that runs from -3 (large negative impact) to 0 (no impact) to +3 (large positive impact). A quick look at the score distributions and totals will help you gauge in advance the wisdom of proceeding and your likelihood of succeeding.

\section{6) Practice What We Preach: Use What We Have}

\section{Learned about Individual and Organizational Learning to Inform and Explain Our Efforts and Strategies}

Those who teach by example and who live their own lessons have the most lasting impact on learners. In a list of six big-ticket items that promote learning, Ewell includes "approaches in which the faculty constructively model the learning process" (1997, p. 5), such as apprenticeships and guided practice. He also notes that "Change requires people to relearn their own roles" (Ewell, 1997, p. 6), suggesting that we cannot hope to transform the teaching and learning process for our students unless we can learn to transform our own mental models and behavior.

Given the research on effective collegiate learning, a fruitful endeavor for many departments would be to develop the faculty member's own skills at working cooperatively toward shared aims. In other words, train faculty in groupwork. Research findings on cooperative learning show that it is one of the most demonstrably effective learning approaches available. As faculty grow more skilled at effective teamwork ourselves, we not only increase our likelihood of success in transforming departments, but also enhance our ability to help our students learn to collaborate effectively.

\section{7) Don't Assume, Ask: Make the Implicit Explicit.}

\section{Use Assessment to Focus on What Matters Most}

At heart, assessment is not about measurement tools and analytical techniques; it is first and foremost about asking the right questions. Whatever we assess-evaluate, measure, judge, mark-is what those being assessed will likely pay more attention to and do more of. Making the assessment process transparent and aligning it with goals and learning activities are critical steps in promoting improved learning outcomes. As Ramsden notes, "From our students' point of view, the assessment always defines the actual curriculum" (1992, p. 187). Thus, assessment is a powerful tool for focusing our attention and efforts. Since attention and effort, like time and energy, are limited resources, we must be very mindful to focus assessment efforts only on what matters most, or we risk wasting those same precious resources. 
At the same time, the ways we assess faculty and students can promote or preclude change by affecting their motivation and fortunes. Recognizing the key role of assessment in change efforts, the Carnegie Foundation for the Advancement of Teaching realized that departments and institutions interested in implementing the recommendations in Boyer's (1990) Scholarship Reconsidered would need a workable framework for assessing the scholarship of teaching. That framework, presented in Scholarship Assessed (Glassick, Huber, \& Maeroff, 1997) will be of use to all change-minded faculty developers. Since grading is the most common form of assessment faculty engage in, and probably the most important to students, making our grading more fair and valid can have far-reaching positive effects. Walvoord and Anderson's Effective Grading (1998) is a comprehensive handbook for those interested in improving this dimension of assessment.

This takes us back to the second and fourth guidelines. We must first decide what our key shared goals are, then determine how we will know if we have achieved them well enough, and only then decide on the instructional and assessment methods and techniques to be used. Throughout the process, of course, we can use assessment methods to uncover tacit differences or misunderstandings by asking questions that will make the implicit explicit. Once a department has developed its tranformative, learning-centered vision and goals, there are several general assessment resources that may be of use, including books by Angelo and Cross (1993), Gardiner, Anderson, and Cambridge (1997), Nichols (1995), and Palomba and Banta (1999).

\section{In Summary: Five Modest First StepS}

All long journeys begin with a single step, the proverb reminds us. Let me sum up by offering not one but five first steps in the journey toward departmental transformation. These five steps mirror Peter Senge's (1990) five disciplines: personal mastery, mental models, shared vision, team learning, and systems thinking.

As a first step toward personal mastery, we must resist the understandable urge to rush the change process. It rarely works. Experience shows that most successful academic innovations take years to bear fruit. We are likely to save time and grief later in the process by taking time at the front end to develop shared trust, shared language, and a small number of shared goals. Second, to explore mental models, in addition to building trust, we can begin by sharing examples of successful teaching 
experiences, definitions of meaningful learning, and examples of exemplary student work. In other words, we can start with a focus on success. Third, building on the first two steps, we can work with faculty to develop a shared vision of what students should know and be able to do at the end of a course, a sequence, or the major-and thus make possible backward design. Fourth, from the beginning, we can promote groupwork and team learning in our departments and units. Since the quality of group process largely determines the productivity of the group, we may need to engage an expert facilitator to teach faculty how to work together effectively as a departmental learning community before they can do the same with students. And fifth, we can apply systems thinking to departmental planning. We might begin by asking how well what we are envisioning fits within the institutional structure and agenda, as well as how it fits into the existing systems of faculty roles and rewards and of students' academic careers.

\section{ACKNowledgment}

The author wishes to thank the scholarly academic developers of the Higher Education Research and Development Society of Australasia (HERDSA), whose ideas and examples have enriched this paper and my professional practice.

\section{REFERENCES}

Angelo, T.A. (1997). The campus as learning community: Seven promising shifts and seven powerful levers." AAHE Bulletin, 49(9), 3-6.

Angelo, T.A., \& Cross, K.P. (1993). Classroom assessment techniques: A handbookfor college teachers (2nd ed.). San Francisco, CA: Jossey-Bass.

Barr, R. B., \& Tagg, J. (1995). From teaching to learning: A new paradigm for undergraduate education. Change, 27 (6), 12-25.

Belenky, M. F., Clinchy, B. M., Goldberger, N. R., \& Tarule, J. M. (1986). Women's ways of knowing: The development of self, voice, and mind. New York, NY: Basic Books.

Biggs, J. (1999). What the student does: Teaching for enhanced learning. Higher Education Research and Development, 18 (1), 55-76.

Boyer, E. L. (1990). Scholarship reconsidered: Priorities of the professoriate. Princeton, NJ: The Carnegie Foundation for the Advancement of Teaching. 
Candy, P. C. (1996). Promoting lifelong learning: Faculty developers and the university as a learning organization. The International Joumal for Faculty development, 1 (1), 7-18.

Cross, K. P. (1998). Why learning communities? Why now? About Campus, 3 (3), 4-11.

Ewell, P. T. (1997). Organizing for learning: A new imperative. AAHE Bulletin, 50(4), 10-12.

Gabelnick, F., MacGregor, J., Matthews, R., \& Smith, B.L. (Eds.). (1990). Learning communities: Creating connections among students, faculty, and disciplines. New Directions for Teaching and Learning, No. 41. San Francisco, CA: Jossey-Bass.

Gardiner, L. F., Anderson, C., \& Cambridge, B. L. (1997). Learning through assessment: A resource guide for higher education. Washington, DC: American Association for Higher Education.

Glassick, C. E., Huber, M. T., \& Maeroff, G. I. (1997). Scholarship assessed: Evaluation of the professoriate. San Francisco, CA: Jossey-Bass.

Johnstone, D. B. (1993). Enhancing the productivity of learning. AAHE Bulletin, 46 (4), 3-5.

Lucas, A. F. (1994). Strengthening departmental leadership: A team-building guide for chairs in colleges and universities. San Francisco, CA: Jossey-Bass.

McKeachie, W. J. (1999). Teaching tips: Strategies, research, and theory for college and university teachers (10th ed.). Boston, MA: Houghton Mifflin.

Millis, B. J. \& Cottell, P.G. (1998). Cooperative learning for higher education faculty. Phoenix, AZ: Oryx.

Nichols, J. O. (1995). A practitioner's handbook for institutional effectiveness and student outcomes assessment implementation. New York, NY: Agathon.

Palomba, C. A., \& Banta, T. W. (1999). Assessment essentials: Planning, implementing, and improving assessment in higher education. San Francisco, CA: Jossey-Bass.

Piaget. (1975). The development of thought: Equilibration of cognitive structures. New York, NY: Viking.

Poulsen, S. J. (1995). Describing an elephant: Specialists explore the meaning of learning productivity. Wingspread Journal, 17 (2), 4-6.

Ramsden, P. (1992). Learning to teach in higher education. London, England: Routledge. 
Ramsden, P. (1998). Learning to lead in higher education (2nd. ed.). London, England: Routledge.

Rice, E. (1991). The new american scholar: Scholarship and the purposes of the university. Metropolitan Universities, I (4), 7-18.

Senge, P. M. (1990). The fifth discipline. New York, NY: Doubleday.

Stark, J. S., Shaw, K. M., \& Lowther, M. A. (1989). Student goals for college and courses. Report No. 6. Washington DC: School of Education and Human Development, The George Washington University.

Tinto, V. (1997). Universities as learning organizations. Aboul Campus, 1 (6), 2-4.

Walvoord, B. E., \& Anderson, V. J. (1998). Effective grading: A tool for learning and assessment. San Francisco, CA: Jossey-Bass.

Wiggins, G., \& McTighe, J. (1998). Understanding by design. Alexandria, VA: Association for Supervision and Curriculum Development.

Contact:

Thomas A. Angelo, Associate Professor and

Director, the SNL Assessment Center

School for New Learning-DePaul University

25 East Jackson Blvd., 2nd Floor

Chicago, IL 60604-2305

(312) $362-5135$

(312) 362-8809 (Fax)

Email: Tangelo@wppost.depaul.edu

URL: http://www.depaul.edu/ tangelo/assessment

Thomas Anthony Angelo is Associate Professor and founding Director of the Assessment Center at DePaul University's School for New Learning, a competency-based liberal arts college for adults. 